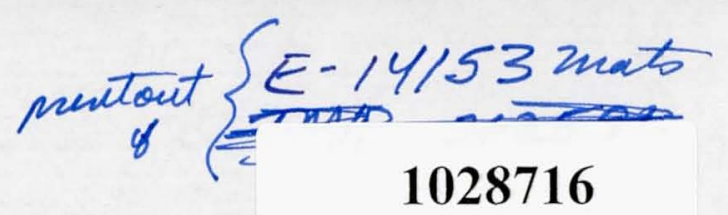

First AIAA/ASME/IEEE International Energy Conversion Engineering Conference

Portsmouth, Virginia

August 17-21, 2003

AIAA-2003-6007

\title{
A POWER CONVERSION CONCEPT FOR THE JUPITER ICY MOONS ORBITER
}

\author{
Lee S. Mason \\ National Aeronautics and Space Administration \\ Glenn Research Center \\ Cleveland, Ohio 44135 \\ Phone: 216-977-7106, Email: Lee.S.Mason@nasa.gov
}

\begin{abstract}
The Jupiter Icy Moons Orbiter (JIMO) is a bold new mission under development by the Office of Space Science at NASA Headquarters. JIMO is examining the potential of Nuclear Electric Propulsion (NEP) technology to efficiently deliver scientific payloads to three Jovian moons: Callisto, Ganymede, and Europa. A critical element of the NEP vehicle is the reactor power system, consisting of the nuclear reactor, power conversion, heat rejection, and power management and distribution (PMAD). The emphasis of this paper is on the non-nuclear elements of the reactor power system.
\end{abstract}

The assumed power level for the NEP vehicle was $100 \mathrm{kWe}$, and a liquid-metal cooled reactor concept was assumed for the study, although both heat-pipe and gas-cooled reactors are possible alternatives. The power conversion system consists of two, independent 100 kWe Brayton cycle converters, providing $100 \%$ converter redundancy. The converter design is based on state-of-the-art superalloy hot-end construction permitting turbine inlet temperatures of $1150 \mathrm{~K}$ and cycle efficiencies in excess of $20 \%$. The only moving part is a single-shaft, radial turbo-compressor which is supported by gas foil bearings. The rotary alternator delivers high voltage, three-phase $\mathrm{AC}$ to the PMAD subsystem. The PMAD concept includes two completely redundant modules, each capable of delivering $100 \mathrm{kWe}$ to the spacecraft. Either PMAD module can service the full suite of thruster power processing units, the spacecraft bus, and the power system parasitic loads. The waste heat rejection system includes a pumped liquid-metal heat transport loop and water heat pipe radiator panels. The heat transport loop interfaces with the Brayton gas coolers, allowing either or both Brayton units to utilize the full radiator surface. The radiator consists of two planar wings, each having a series of stair-cased deployable rectangular panels that are contained within the radiation shield half-angle

*Research Engineer.

Copyright (C) 2003 by the American Institute of Aeronautics and Astronautics, Inc. No copyright is asserted in the United States under Title 17, U.S. Code. The U.S. Government has a royalty-free license to exercise all rights under the copyright claimed herein for Governmental purposes. All other rights are reserved by the copyright owner. and provide two-sided heat rejection. This paper discusses some of the key trade-offs considered in arriving at the baseline concept and provides a summary of the power system performance and mass.

\section{INTRODUCTION}

The Jupiter Icy Moons Orbiter (JIMO) mission is an element of NASA's Project Prometheus Program. The JIMO mission is studying the potential of Nuclear Electric Propulsion (NEP) to deliver scientific payloads to the Jovian moons of Callisto, Ganymede, and Europa. A NEP vehicle concept was developed, and trade studies were performed, to accomplish JIMO. The power and propulsion module consisted of a $100 \mathrm{kWe}$ reactor power system and a 6800 second specific impulse, ion propulsion system. A general block diagram for the NEP vehicle concept is shown in Figure 1.

The emphasis of this paper is on the non-nuclear elements of the reactor power system including the power conversion, heat rejection, and power management and distribution (PMAD). A liquid-metal (lithium) cooled reactor concept was assumed for the study, although both heat-pipe and gas-cooled reactors are possible alternatives. The reactor includes a truncated conical radiation shield with a 10 degree half angle that attenuates induced radiation levels to $25 \mathrm{krad}$ and $1 \times 10^{11}$ neutrons $/ \mathrm{cm}^{2}$ at the payload located 30 meters from the reactor. The reactor also includes a liquid-metal to gas heat exchanger that accommodates the integration of a Closed Brayton Cycle (CBC) power conversion system. The $\mathrm{CBC}$ conversion system was selected for the study based on its high efficiency and

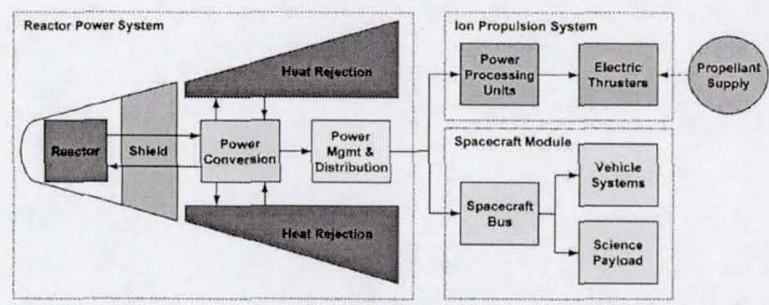

Figure 1. NEP Vehicle Block Diagram 
suitability for the power level of interest. Stirling and thermoelectric conversion technologies are also under consideration. The heat rejection and PMAD concepts are oriented to $\mathrm{CBC}$ power conversion, although aspects of the designs would be applicable to the other conversion options.

\section{TRADE STUDIES}

There were many conceptual design trade studies that were conducted related to the power subsystems. System-level studies examined design and off-design operating modes, determined startup requirements, evaluated subsystem redundancy options, and quantified the mass and radiator area of reactor power systems from 20 to $200 \mathrm{kWe}$. The majority of this activity centered around Brayton cycle analysis and optimization, aimed at defining cycle performance and subsystem interface requirements. In the Brayton converter subsystem, studies were performed to investigate converter packaging options, and assess the induced torque effects on spacecraft dynamics due to rotating machinery. In the heat rejection subsystem (HRS), design trades were conducted on heat transport approaches, material and fluid options, and deployed radiator geometries. In the PMAD subsystem, the overall electrical architecture was defined and trade studies examined distribution approaches, voltage levels, and cabling options.

\section{REACTOR POWER SYSTEM}

The power system conceptual design process is iterative and involves technology assessments, systems analysis, subsystem design, and vehicle integration studies. Technology assessments provide a basis for selecting design parameters that are consistent with launch date. Some examples of important design parameters are reactor outlet temperature, radiator panel areal mass (defined as mass per unit area or $\mathrm{kg} / \mathrm{m}^{2}$ ), and alternator output voltage. These must be selected based on current Technology Readiness Levels (TRL) and realistic projections for technology advancement prior to launch. Systems analysis is conducted using the technology design parameters as inputs to analytical models to arrive at an initial concept. Subsystem design provides further definition and serves to either substantiate or revise the design parameter assumptions. Finally, vehicle integration studies examine the feasibility of the design working within the spacecraft and mission framework. At each stage in the process, new information usually causes the designers to reassess previous assumptions and adjust the overall concept. The sections below describe some of the system-level trades conducted during the study.

\section{Cycle Analysis}

The power systems analysis was performed using a Glenn Research Center computer model called
NUCOPT, which accounts for the reactor, power conversion, heat rejection, and PMAD subsystems. 'The Brayton cycle state point diagram at the conclusion of the study process is shown in Figure 2. The Brayton converter interfaces to the reactor through the heat source heat exchanger (HSHX), to the main radiator through the gas cooler, and to the PMAD through the alternator. An inert gas mixture (HeXe) is used as the Brayton working fluid. The only moving part is a single-shaft, radial turbo-compressor which is supported by gas foil bearings.

The power system design included two independent $100 \mathrm{kWe}$ converters, based on a proposed mission requirement to provide "fail-op" redundancy (defined as continued full power capability after component failure) in the power conversion subsystem. The HSHX gas outlet temperature was set at $1150 \mathrm{~K}$, allowing the use of nickel-based superalloys for the hot-end converter components. Figure 3 reveals an aspect of the cycle optimization process-showing reactor power, radiator area, and power conversion mass sensitivity to compressor inlet temperature. The minimum mass design point occurs at a compressor inlet temperature of $411 \mathrm{~K}$. The cycle analysis assumed component efficiencies of $90 \%$ for the turbine, $80 \%$ for the compressor, and $92 \%$ for the alternator, and the recuperator effectiveness was set at $95 \%$. Bearing and

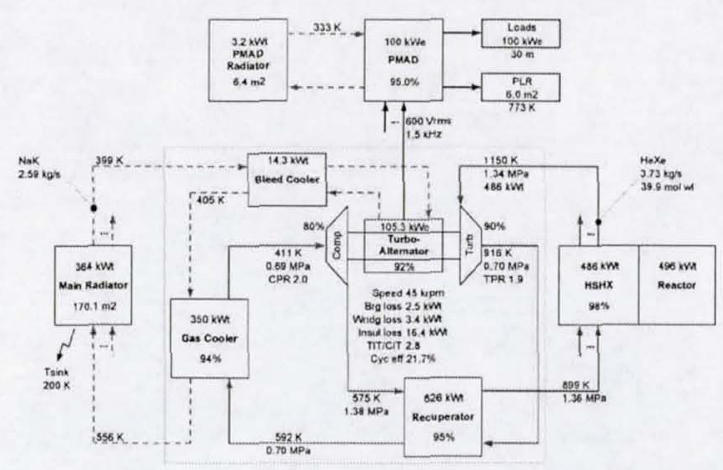

Figure 2. Brayton Cycle Diagram

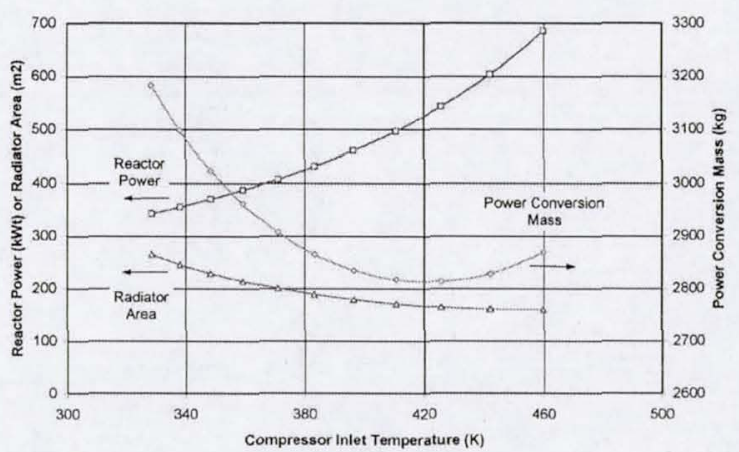

Figure 3. Brayton Cycle Optimization 
alternator windage losses were 2.5 and $3.4 \mathrm{kWt}$, respectively. Insulation losses were estimated at $16.4 \mathrm{kWt}$. The design point Brayton cycle efficiency was $21.7 \%$ and the total end-to-end power system efficiency was $20.2 \%$, resulting in a required reactor thermal power of $496 \mathrm{kWt}$.

Brayton heat rejection is accomplished with a pumped $\mathrm{NaK}$ heat transport loop and a two-sided main radiator having a total surface area of $170 \mathrm{~m}^{2}$. The total waste heat load was $364 \mathrm{kWt}$, comprised of $350 \mathrm{kWt}$ from the gas cooler and $14 \mathrm{kWt}$ from an alternator bleed cooler. The alternator bleed cooler provides waste heat dissipation for bearing, windage, and alternator electromagnetic losses. The radiator area was determined based on an effective sink temperature of $200 \mathrm{~K}$, fin effectiveness of $92 \%$, and surface emissivity of 0.9 .

The three-phase alternator produces $105 \mathrm{kWe}$ at $45000 \mathrm{rpm}, 600 \mathrm{Vrms}$ line-to-line, and $1.5 \mathrm{kHz}$. The $95 \%$ efficient PMAD system delivers $100 \mathrm{kWe}$ to the loads over a 30 meter transmission distance. The PMAD includes power and control electronics, switchgear, and cabling. Also included is a full power shunt Parasitic Load Radiator (PLR) and a separate PMAD thermal control radiator. The PLR has an effective temperature of $773 \mathrm{~K}$ and a surface area of $6 \mathrm{~m}^{2}$. The $6.4 \mathrm{~m}^{2} \mathrm{PMAD}$ radiator maintains an electronics cold-plate temperature at $333 \mathrm{~K}$ under a $3.2 \mathrm{kWt}$ heat load.

\section{Operating Modes}

Additional cycle analyses were performed to examine off-design operating modes for the Brayton converters. The sizing condition for the Brayton components was based on $100 \mathrm{kWe}$ output, under a "converter-out" condition. Nominally, the two Brayton units would operate at $50 \%$ power. This is achieved by operating the units at a lower rotor speed and charge pressure. The lower rotor speed results in an alternator voltage decrease to $400 \mathrm{Vrms}$ line-to-line. The major benefit of operating the units at part power is a reduction in the thermal stresses and bearing loads. However, the reactor thermal power increases to $554 \mathrm{kWt}$ for the nominal operating mode, due to a modest decrease in cycle efficiency. An alternative approach is to operate a single unit and maintain a cold-standby unit.

Another operating mode that was considered was the minimum power coast mode. This mode would be utilized during interplanetary coasting (electric thrusters off) and upon arrival at the Jupiter moon science orbits. The goal was to reduce reactor thermal power and operating temperature to minimize fission product buildup, thermal stress, and material creep. The HSHX gas outlet temperature was set at $950 \mathrm{~K}$. The Brayton unit output power and reactor thermal power was determined based on the need to maintain the $\mathrm{NaK}$ radiator coolant above its freezing temperature of $262 \mathrm{~K}$ without re-stowing radiator panels. The resulting cycle analysis, assuming off-design component efficiencies, indicated that the system output power could be reduced to $20 \mathrm{kWe}$ with a corresponding reactor thermal power of $118 \mathrm{kWt}$. Alternatively, the reactor power system could be operated at full power throughout the mission, and the PLR could be utilized to shunt any excess power not required by the loads.

\section{Startup Power}

A representative startup approach was defined for the reactor power system, based on electrical power provided from the spacecraft bus solar arrays and/or batteries. Startup is initiated by energizing the PMAD controller and reactor instrumentation and control (I\&C) subsystem. After the reactor is started to $10 \%$ thermal power, the first radiator wing is partially deployed and oriented to the sun for heating. The radiator wing is charged with coolant and the pump is started. Then the first Brayton unit is electrically motored (or rotated) to circulate the HeXe working fluid for approximately 15 minutes before a selfsustaining condition is achieved and positive power is being produced. As the reactor power is increased to $50 \%$ and full deployment of the first radiator wing is completed, the Brayton unit ramps to nominal operating power. At that point, all of the spacecraft loads would be transferred from the spacecraft bus to the alternator bus. The total time to achieve bus switch-over was estimated at 4 hours, and startup energy for the power system was approximately $1 \mathrm{~kW}-\mathrm{hr}$. Deployment of the second radiator wing and startup of the second Brayton unit would be accomplished from the alternator bus.

A hot restart following a Brayton converter shutdown was estimated to require less than $0.2 \mathrm{~kW}-\mathrm{hr}$. The large thermal capacitance of the reactor and converter units should permit hot restarts for several hours following an unexpected shutdown, the limiting factor being the freezing of the radiator coolant.

\section{Redundancy Trades}

The mass of the Brayton converters, heat rejection, and PMAD for the baseline configuration was estimated at $2818 \mathrm{~kg}$. This mass was based on two $100 \mathrm{kWe}$ Brayton units, two $100 \mathrm{kWe}$ PMAD modules, and a heat rejection subsystem capable of dissipating the waste heat from a single Brayton unit at $100 \mathrm{kWe}$ or two units at $50 \mathrm{kWe}$ each. Alternatives to this configuration were evaluated relative to the full power capacity of the individual subsystems. Table 1 shows the mass differences for several alternative configurations. A single-string architecture would provide a $982 \mathrm{~kg}$ mass savings, whereas a configuration with full $100 \%$ redundancy in the converters, radiators, and PMAD 
would incur a $854 \mathrm{~kg}$ mass penalty. Configurations with greater than three Brayton units were not judged practical due to constraints in vehicle packaging and reactor interface piping.

Table 1. Mass Versus Subsystem Redundancy

\begin{tabular}{|c|c|c|c|c|c|c|}
\hline $100 \mathrm{kWe}$ Net & $\begin{array}{l}\text { Single- } \\
\text { String }\end{array}$ & & 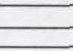 & $\begin{array}{l}\text { JIMT } \\
\text { Rer. }\end{array}$ & $\longrightarrow$ & $\begin{array}{c}\text { Full } \\
\text { Redundancy }\end{array}$ \\
\hline Braytons & $1 \times 100 \%$ & $1 \times 100 \%$ & $2 \times 50 \%$ & $2 \times 100 \%$ & $3 \times 50 \%$ & $2 \times 100 \%$ \\
\hline Radistors & $1 \times 100 \%$ & $2 \times 50 \%$ & $2 \times 50 \%$ & $2 \times 50 \%$ & $3 \times 50 \%$ & $2 \times 100 \%$ \\
\hline PMAD & $1 \times 100 \%$ & $2 \times 100 \%$ & $2 \times 50 \%$ & $2 \times 100 \%$ & $3 \times 50 \%$ & $2 \times 100 \%$ \\
\hline Mass $(\mathrm{kg})$ & 1836 & 2178 & 2362 & 2818 & 3543 & 3672 \\
\hline Rel. Mass $(\mathrm{kg})$ & -982 & -640 & -456 & 0 & +725 & +854 \\
\hline
\end{tabular}

\section{Power Level Scaling}

Figure 4 shows the mass and radiator area of the reactor power system for power levels from 20 to $200 \mathrm{kWe}$, based on the reference configuration. The total reactor power system mass for the $100 \mathrm{kWe}$ design concept was $4115 \mathrm{~kg}$, or $41 \mathrm{~kg} / \mathrm{kWe}$. A $20 \mathrm{kWe}$ system has a specific mass of about $100 \mathrm{~kg} / \mathrm{kWe}$, while a $200 \mathrm{kWe}$ system has a specific mass of $32 \mathrm{~kg} / \mathrm{kWe}$ due to the favorable scaling characteristics of reactor-Brayton technology. Radiator area is relatively linear over this power range, since the basic cycle temperatures were not varied.

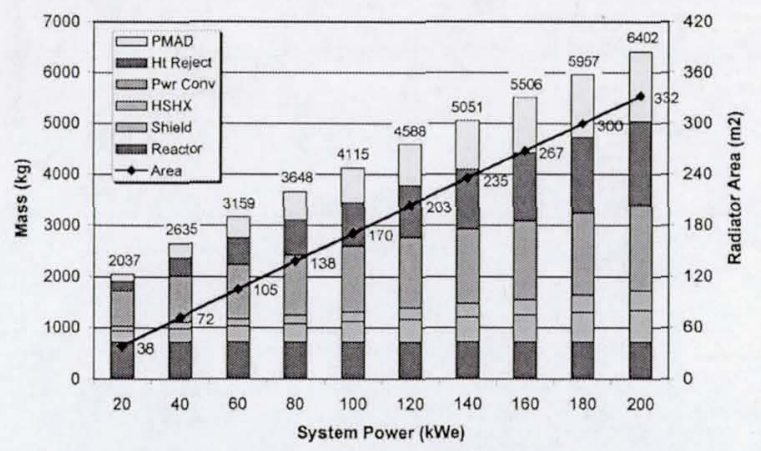

Figure 4. System Mass Versus Power

\section{BRAYTON SUBSYSTEM}

The Brayton cycle analysis discussed previously provides the basis for the Brayton subsystem design. The input design parameters are derived from previous converter development activities such as the $10 \mathrm{kWe}$ Brayton Rotating Unit (BRU), $2 \mathrm{kWe}$ mini-BRU, and 25 kWe Space Station Freedom (SSF) Solar Dynamic Power Module. ${ }^{2-4}$ Despite over 30 years of NASA technology development, Brayton power converters have never been operated in space. The BRU system, including the Brayton Heat Exchanger Unit (BHXU) recuperator/cooler, represents the longest duration ground test of a $\mathrm{CBC}$ conversion system at
38000 hours. Both the BRU and mini-BRU units were fabricated using nickel-based superalloys for the hot-end components which allow turbine inlet temperatures of about $1150 \mathrm{~K}$. Scaling these designs to the $100 \mathrm{kWe}$-class seems achievable within the anticipated development timeline. However, life validation prior to launch will be a significant challenge. The proceeding sections discuss some of the Brayton-specific trades conducted during the study.

\section{Converter Packaging}

The Brayton converter subsystem consists of the turboalternator, recuperator, and gas cooler. Several converter layout options were considered as shown in Figure 5. The "stacked" layout approach was preferred based on a smaller cross-sectional diameter. This allowed the Brayton units to be located closer to the reactor to minimize interface piping length without adversely effecting shield half angle and shield mass. The overall assembly with the two $100 \mathrm{kWe}$ units was $1.8 \mathrm{~m}$ in cross-section diameter and $2.6 \mathrm{~m}$ in length.
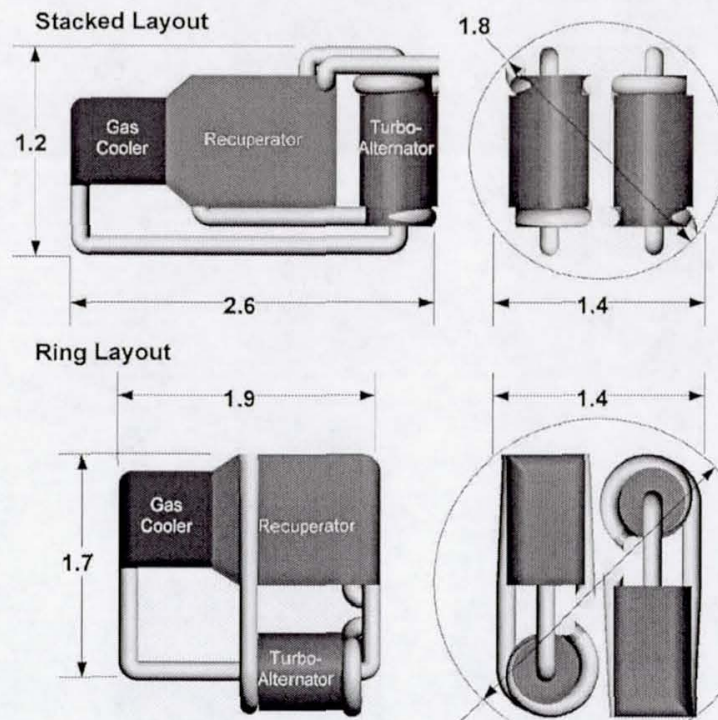

Figure 5. Converter Layout Options

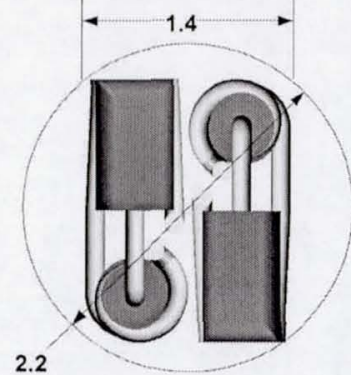

Torque Effects

A first-order analysis was performed using SIMULINK to understand the effects of induced torque from rotating machinery on NEP vehicle dynamics. The analysis considered a representative $100 \mathrm{kWe}$ NEP vehicle with dual Brayton units. Each Brayton unit includes a $53 \mathrm{~cm}$ long, $23 \mathrm{~kg}$ rotating assembly with two radial journal bearings and one axial thrust bearing. Primary variables included bearing stiffness (soft and hard), rotor orientation (parallel and transverse to vehicle truss), and operating scenarios (counter and co-rotating). Startup and shutdown events were also analyzed. 
Table 2. Torque Study Summary

\begin{tabular}{|l|c|c|c|}
\hline $\begin{array}{l}\text { Two co-rotating Brayton units } \\
\text { Rotor axis parallel with vehicle truss } \\
2000 \text { Ib/in bearing stiffness }\end{array}$ & $\begin{array}{c}\text { S/C } \\
\text { Axis }\end{array}$ & $\begin{array}{c}\text { Max } \\
\text { Torque } \\
\left(\mathbf{N}^{*} \mathbf{m}\right)\end{array}$ & $\begin{array}{c}\text { Max } \\
\text { Accel } \\
\left(g^{\prime} \mathbf{s}\right)\end{array}$ \\
\hline Steady State Net Bias Torque & R/P/Y & 0 & 0 \\
\hline $\begin{array}{l}\text { Steady State Cyclical Torque } \\
\text { (Due to assumed rotor imbalance) }\end{array}$ & Roll & 0.04 & $6 \times 10^{-7}$ \\
\cline { 2 - 4 } & P/Y & 26 & $3 \times 10^{-5}$ \\
\hline $\begin{array}{l}\text { Single Unit Startup } \\
\text { Transient Torque } \\
\text { (Nominal case, 0 to } 50 \mathrm{krpm} \text { in 10 sec) }\end{array}$ & Roll & 20 & $3 \times 10^{-4}$ \\
\hline $\begin{array}{l}\text { Single Unit Shutdown } \\
\text { Transient Torque } \\
\text { (Worst case, } 50 \mathrm{krpm} \text { to } 0 \text { in } 1 \mathrm{sec} \text { ) }\end{array}$ & $\mathrm{Poll}$ & 17 & $2 \times 10^{-5}$ \\
\cline { 2 - 4 } & $\mathrm{P} / \mathrm{Y}$ & 17 & $2 \times 10^{-5}$ \\
\hline
\end{tabular}

Spacecraft moment of inertias very preliminary and conservative Roll $=5000 \mathrm{Kg}-\mathrm{m}^{2}$, Pitch $/$ aw $=574,000 \mathrm{Kg}-\mathrm{m}^{2}$

A sampling of the results is provided in Table 2 . The net bias torque during steady-state operation is zero. Some low level cyclical torque is possible due to an assumed (very slight) rotor imbalance. A nominal 10 second rotor spin-up resulted in a $20 \mathrm{~N}$-m transient torque. A worst-case, 1 second rotor shutdown resulted in a $196 \mathrm{~N}-\mathrm{m}$ transient torque. These temporary torques would have to be countered by the vehicle's reaction control system. Parallel versus transverse mounting had no significant effect on vehicle dynamics. Counter versus co-rotating also had no significant effect. However, counter-rotating pairs would minimize gyroscopic precession effects on vehicle maneuvers.

\section{Turbine Inlet Temperature}

The Brayton turbine inlet temperature (or HSHX gas outlet temperature) is a key parameter that influences performance. Higher temperatures allow increases in cycle efficiency or decreases in radiator area, or a combination of both. However, the higher operating temperatures tend to increase mission risk since more advanced materials are required to handle the higher thermal stress. The baseline turbine inlet temperature was $1150 \mathrm{~K}$. Temperatures above about $1200 \mathrm{~K}$ would require refractory alloys for the hot-end components. Figure 6 shows power conversion system mass and radiator area as a function of turbine inlet temperature. A turbine inlet temperature of $1450 \mathrm{~K}$ would provide a $20 \%$ reduction in mass and a $55 \%$ reduction in radiator area relative to the $1150 \mathrm{~K}$ reference.

\section{HEAT REJECTION SUBSYSTEM}

The HRS dominates the NEP vehicle layout, due to the large size of the radiator surface. However, a precedent exists for large space radiators with the International Space Station (ISS) Photovoltaic Radiator (PVR). ${ }^{6}$ The PVR is a pumped ammonia heat rejection system with deployable radiator panels. A radiator assembly includes seven 2 -sided panels in series, each measuring 1.82 by 3.35 meters, for a total surface area of approximately $85 \mathrm{~m}^{2}$. The aluminum honeycomb radiator panels are deployed using a scissor mechanism,

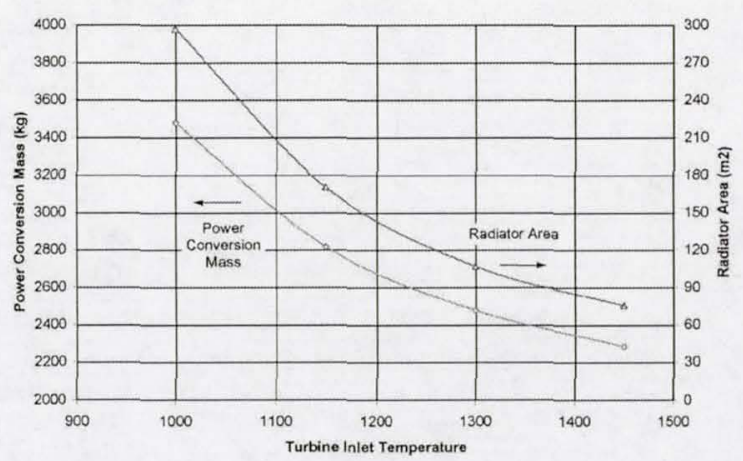

Figure 6. Mass and Area Versus Turbine Inlet Temperature

and the total heat rejection (panels, fluid loop, deployment mechanism) areal mass is $8.8 \mathrm{~kg} / \mathrm{m}^{2}$ (based on total surface area). The individual radiator panels are approximately $1.8 \mathrm{~cm}$ thick with an areal mass of about $2.75 \mathrm{~kg} / \mathrm{m}^{2}$ (based on total surface area).

During the SP-100 Space Reactor Program, ${ }^{7}$ advanced radiator studies were performed by four different contractor teams. The studies addressed radiator designs for operating temperatures of 600 and $875 \mathrm{~K}$. One contractor completed a successful fabrication and test of a high temperature radiator element utilizing a potassium heat pipe and carbon-carbon fin structure. ${ }^{8}$ The condensing section was approximately $91 \mathrm{~cm}$ long and $7.5 \mathrm{~cm}$ wide with a $2.5 \mathrm{~cm}$ diameter $\mathrm{Nb}-1 \mathrm{Zr}$ heat pipe. The integrated heat pipe and fin assembly had an areal mass of $2.1 \mathrm{~kg} / \mathrm{m}^{2}$ (based on total surface area).

The HRS for the NEP concept study included heat transport, radiator panels, and deployment mechanism. Both the ISS radiator and the SP-100 advanced radiator studies were leveraged in arriving at the design concept. Some of the HRS design trades are discussed below.

\section{Heat Transport Approach}

A significant challenge for the heat rejection subsystem was to develop a heat transport approach to accommodate the dual-redundant Brayton power converter architecture. In order to maintain "fail-op" redundancy in the conversion system and avoid the need to carry twice the required radiator area, a crossstrapped pumped heat transport loop was devised as shown in Figure 7. The two Brayton gas coolers serve as the thermal interface to the coolant loops. Each coolant loop has dual redundant electromagnetic pumps. Each gas cooler includes two independent liquid passages, or cores, and one gas passage. During nominal operation, when both Brayton units are operating at $50 \%$ power, the liquid coolant flows through one of the liquid passages where the full waste heat load is transferred to the coolant. The coolant is 


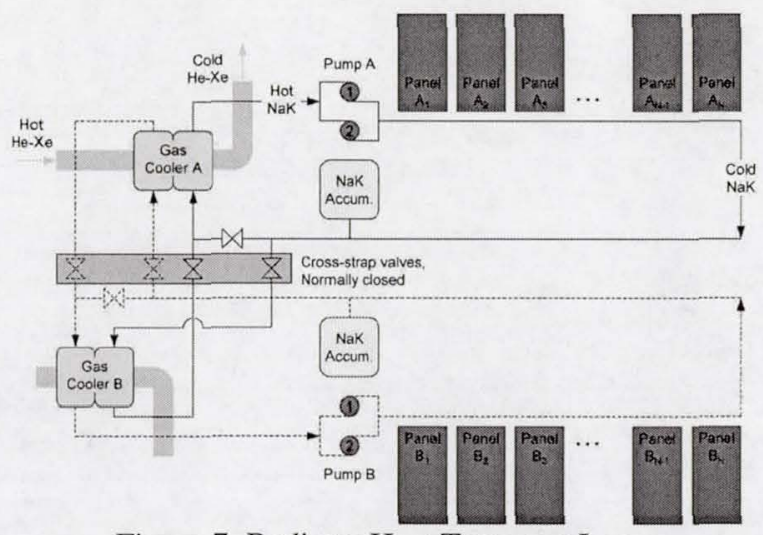

Figure 7. Radiator Heat Transport Loop

then pumped through manifolds along a series of interconnected radiator panels, forming a radiator wing assembly. The waste heat is transferred through heat pipes to the two-sided radiator surface where it is rejected to space. Each radiator wing assembly is sized to reject one-half of the total waste heat load.

In the event of a converter outage, the two pumped coolant loops continue to operate as before: coolant flow rates and operating temperatures are maintained at near-nominal conditions. However, a series of crossstrapping valves are actuated that allow both coolant loops to service the remaining gas cooler. The gas cooler heat load is increased by approximately a factor of two as the operating converter's power output is doubled to maintain full system power. Both coolant loops continue to transfer the heat to their respective radiator assemblies, which continue to dissipate onehalf of the total waste heat load.

\section{Fluids and Materials}

The reference HRS design uses NaK coolant and water heat pipes. $\mathrm{NaK}$ provides a high specific heat coolant over a wide temperature band suitable to the Brayton cycle conditions. Alternative coolant options include hydrocarbons, fluorocarbons, organics, and water. The coolant loop containment material is stainless steel. The water heat pipes interface to the $\mathrm{NaK}$ coolant through evaporator sections that are contained in the fluid loop. Heat pipes provide an efficient means of spreading the heat across the radiator surface with minimal temperature drop. The heat pipes also provide greater fault tolerance than a system with pumped loop radiator panels, since the failure of an individual heat pipe would have minimal system performance impacts. The use of high-pressure water as the heat pipe fluid provides good heat transfer at suitable temperatures with relatively low risk. The heat pipe fluid containment material is stainless or nickel-based.
The radiator panels are constructed of a composite material such as carbon-carbon. Composite materials provide low mass, high conductivity and reasonable stiffness. The assumed areal mass of the heat pipe radiator panels was $2.75 \mathrm{~kg} / \mathrm{m}^{2}$ (based on total surface area). The total HRS areal mass including radiator panels, pumped coolant loop, and deployment system was $5 \mathrm{~kg} / \mathrm{m}^{2}$ (based on total surface area). The mass of the pumped coolant loop was calculated based on estimates for piping lengths, pump capacity, accumulator size, and fluid volume. The mass of the deployment system was calculated based on $30 \%$ of the radiator panel mass.

\section{Radiator Geometry and Deployment}

The main power conversion radiators have a total surface area of $170 \mathrm{~m}^{2}$. Several options were considered in packaging the radiators on the NEP vehicle as shown in Figure 8. An important constraint is the reactor radiation shield cone angle. Components that are outside the shielded cone are subjected to considerably higher induced radiation levels. Since the radiators are expected to have materials and fluids that might degrade from radiation, a decision was made to maintain the full radiator surface within the shield cone angle. Maintaining the radiator panels within the cone angle also reduces the potential for reactor radiation scattering at the payload end of the vehicle.

The layouts in Figure 8 assume a $10^{\circ}$ shield half angle and a 9 meter total axial length for the "up-front" equipment: reactor, shield, Brayton units, coolant pumps and accumulators, and truss canister. The deployable truss has a square cross-section with a 0.7 meter side. The upper layout was selected for the reference concept. This configuration uses a "staircase" geometry consisting of ten 1.5 meter panels per wing with a $10 \mathrm{~cm}$ gap between panels. The first panel has a deployed height of 1.5 meters, while the last panel has a deployed height of about 4.1 meters. The advantage of this geometry is the relatively short overall length of the radiator panels ( 16 meters) which helps to reduce the mass of the radiator piping, truss, and power cabling.
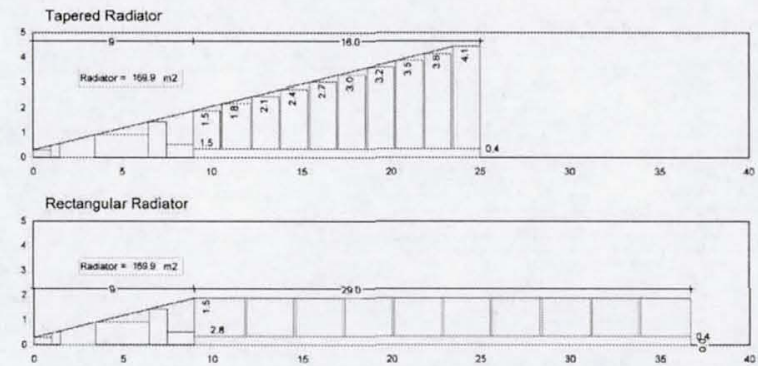

Figure 8. Radiator Geometry Options 
The lower layout utilizes ten identical 1.5 by 2.8 meter panels per wing. This geometry offers greater simplicity in panel fabrication and radiator deployment, but results in a significantly greater overall radiator length (29 meters).

Deployment of the panels is accomplished with a scissor mechanism, similar to the ISS radiators, that is attached to the panels along the truss edge. Each radiator wing is assumed to have its own deployment mechanism, allowing the wings to be deployed separately and independently from the truss. The separate radiator deployment permits greater flexibility for power system startup, as described previously. It also removes the complexity of coincident truss deployment and reactor startup.

Figure 9 shows the effect of shield half angle on radiator length and relative shield mass for a range of radiator areas from 100 to $250 \mathrm{~m}^{2}$. The curves assume a 9 meter "up-front" equipment length and the "staircase" radiator geometry with 10 panels per wing. An increase in the shield half angle from 10 to $15^{\circ}$ would reduce the overall radiator length by about $25 \%$. However, the relative shield mass would increase by about $50 \%$.

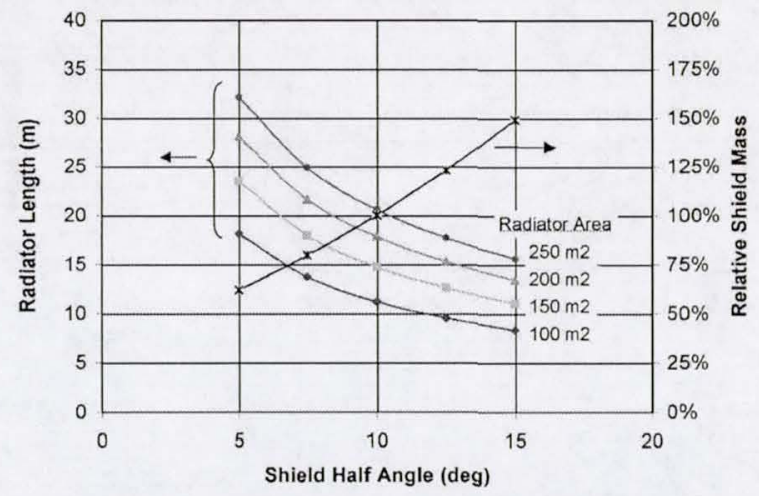

Figure 9. Shield Half Angle Sensitivities

\section{POWER MANAGEMENT AND DISTRIBUTION}

The PMAD subsystem is an often overlooked, but highly critical element of the reactor power system. This is particularly true for NEP systems that include high voltage electric thruster loads. The PMAD subsystem accepts the electrical output of the converters, modifies it as required by the bus, and distributes the power to the loads. In addition, PMAD provides control and health monitoring for the power conversion subsystem.

Similarly to the HRS, the International Space Station provides a useful reference for the PMAD concept. The ISS represents the largest power system ever developed for space, with power levels approaching $100 \mathrm{kWe}$ at assembly complete. The ISS uses a $120 \mathrm{Vdc}$ primary bus architecture with modular channels. The ISS PMAD system includes several components which provide a notional starting point for NEP designs, including remote power controllers, switchgear, and shunts. Additional PMAD technology efforts are pursuing higher voltage space-rated electronic components including relays, fuses, and switchgear for $270 \mathrm{Vdc}$.

A significant challenge for the PMAD subsystem for the JIMO mission is the reactor-induced radiation environment, coupled with the severe natural radiation environment at Jupiter. Total cumulated gamma dose at the electronics dose plane for the JIMO mission is estimated at approximately $4.3 \mathrm{Mrad}$, while total neutron dose is estimated at $6 \times 10^{12}$ neutrons $/ \mathrm{cm}^{2}$ (based on 100 mil aluminum shielding of the electronics). The contribution of the reactor to the total dose levels anticipated at the electronics is $25 \mathrm{krad}$ and $1 \times 10^{11}$ neutrons $/ \mathrm{cm}^{2}$. This radiation environment is well beyond the present state-of-the-art in radiation tolerant high power PMAD components.

The PMAD subsystem concept was developed from a bottoms-up approach. The study included analysis of power electronics, switchgear, electrical control, thermal control, and power cabling. The proceeding sections describe some of the PMAD-specific trades conducted during the study.

\section{PMAD Architecture}

Before any comparative analysis could be performed on the PMAD subsystem, an electrical architecture was required. Figure 10 shows the basic block diagram. Each of the two Brayton alternators has its own dedicated PMAD module, sized for $100 \mathrm{kWe}$. The alternator power is delivered to a $400 \mathrm{Vac}, 1 \mathrm{kHz}$ PMAD bus within the PMAD module. A buck transformer is provided at the input of the PMAD bus to reduce alternator voltage from 600 to $400 \mathrm{Vac}$, for the off-nominal case when a single alternator is providing the full $100 \mathrm{kWe}$ system power. Additional work is needed to assess the PMAD performance for the minimum power coast mode condition, with two Brayton units at $10 \mathrm{kWe}$ each.

From the PMAD bus, power is distributed to switchgear for the electric thruster PPUs, the spacecraft bus, the PLR controller, and the power system auxiliary loads. The PMAD module also includes a start inverter for motoring the alternator during startup and a computer processor for overall PMAD control. A $333 \mathrm{~K}$ coldplate provides a thermal control interface for the PMAD radiator. 


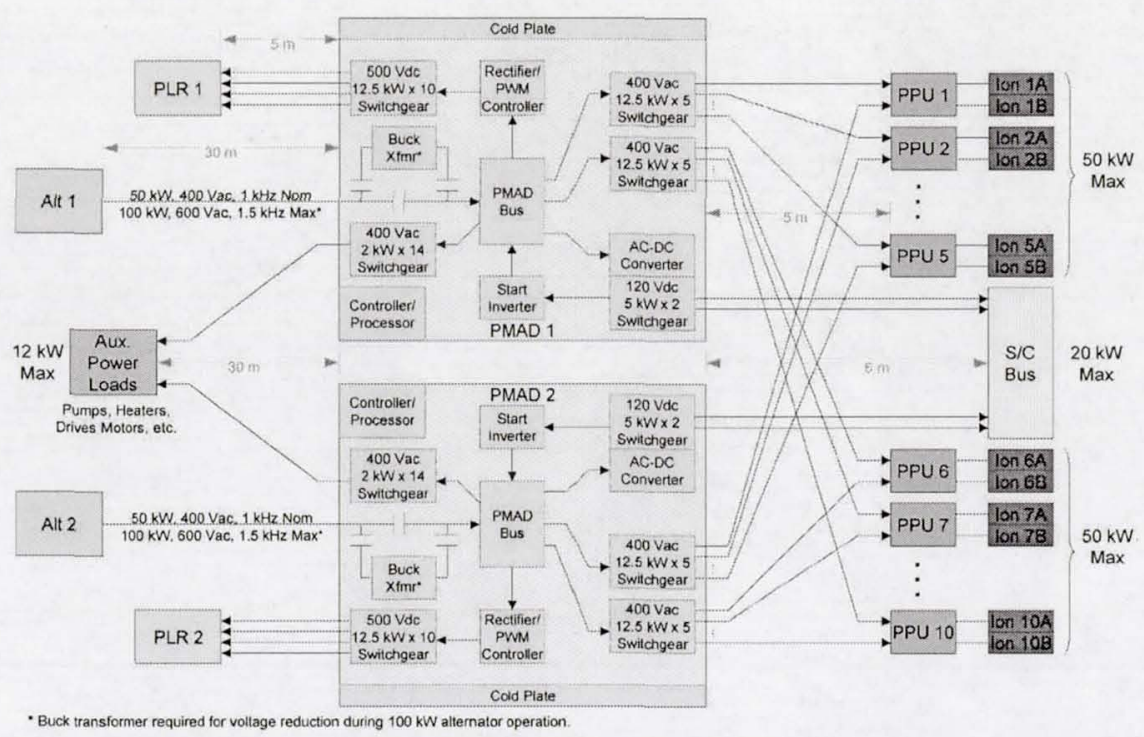

Figure 10. PMAD Architecture

The Electric Propulsion (EP) system includes ten PPUs and two ion thrusters per PPU. The PPU power distribution approach provides considerable redundancy and fault tolerance. The EP design concept includes a complete second set of thrusters to accommodate wearout of the first set, and two redundant thrusters per set. A maximum of eight thrusters can be operated at any one time. A single PMAD module provides power switching to all ten PPUs at $400 \mathrm{Vac}$ and $12.5 \mathrm{kWe}$ per channel. During full power EP operation (i.e. $100 \mathrm{kWe)}$ with both Brayton units operating at $50 \mathrm{kWe}$, each PMAD module powers only four of the ten PPU channels. If a single Brayton unit is operating at $100 \mathrm{kWe}$, eight of the ten PPU channels are powered. The PPU converts the $400 \mathrm{Vac}$ to $4000 \mathrm{Vdc}$ via a transformer/rectifier/filter for the main beam power supply load. Lower power ancillary thruster loads (cathodes, heaters, etc.) are supplied via a 120 Vdc AC-DC converter in the PPU.

The PMAD subsystem delivers $120 \mathrm{Vdc}$, and up to $20 \mathrm{kWe}$ to the spacecraft bus. Each PMAD module can provide up to $10 \mathrm{kWe}$ in two $5 \mathrm{kWe}$ channels. The spacecraft bus delivers secondary power, at lower voltages if necessary, to all the vehicle subsystems (e.g. communications, avionics, etc.) and to the science instrument payload. The 400 Vac PMAD bus power is converted to $120 \mathrm{Vdc}$ via an AC-DC converter. The PMAD switchgear interface with the spacecraft bus also serves as a power feed to the start inverter for alternator motor startup.

The PLR controller provides pulse-width modulated (PWM) switching of the PLR resistor elements to maintain constant alternator speed and load regardless of external power demands. This approach has been successfully implemented on previous Brayton systems. ${ }^{9}$ Each PMAD module includes a dedicated $500 \mathrm{Vdc}$ PLR load bank sized to dissipate up to $100 \mathrm{kWe}$ at $773 \mathrm{~K}$.

The power system auxiliary load bus provides electrical power for coolant pumps, heaters, drive motors and instrumentation using a $400 \mathrm{Vac}$ distribution system. The switchgear and cabling was sized for up to fourteen $2 \mathrm{~kW}$ loads, assumed to be located in the general vicinity of the Brayton units.

Equipment Layout and Cabling Distance

The cabling distances indicated in Figure 10 represent a reference power distribution layout for the study. The reference layout has the PMAD subsystem located at the payload end of the vehicle, with 30 meters of cabling provided between the Brayton alternators and PMAD. The PMAD modules are within close proximity ( $\leq 5$ meters) of the electric thruster PPUs, spacecraft bus, and PLR. The auxiliary load bus is co-located with the Brayton units at the reactor end of the vehicle. The location of the PMAD modules at the payload end of the vehicle allows the electronic equipment to share shielding with other electrical systems. This helps to minimize the spot shielding required for vehicle electronics.

The power cabling assumed for the study was tincoated, copper conductor with Tefzel insulation, similar to what is used on the ISS, rated for 600 Volts and $150{ }^{\circ} \mathrm{C}$. Table 3 provides a summary of the cable sizes. All of the cables were de-rated for current carrying capacity per MIL-STD-975L, for operating 
temperature, and for bundling. The total power cabling mass for the five cable assemblies (alternator-toPMAD, PMAD-to-PPU, PMAD-to-bus, PMAD-toPLR, and PMAD-to-aux) associated with one PMAD module was $77 \mathrm{~kg}$. Prior to arriving at the final power distribution layout, several alternatives were considered including locating the PMAD near the Brayton alternators. The cabling mass penalty was relatively small at about $10 \%$, but the radiation shielding mass penalty was projected to be significant.

Table 3. PMAD Cable Sizing

\begin{tabular}{|l|c|c|c|c|c|c|}
\cline { 2 - 7 } \multicolumn{1}{c|}{} & $P(\mathrm{KW})$ & Volts & Ncond & Amps & AWW & $\mathrm{L}(\mathrm{m})$ \\
\hline Alt-PMAD & 100 & $600 \mathrm{Vac}$ & 6 & 53 & 4 & 30 \\
\hline PMAD-PPU & 125 & $400 \mathrm{Vac}$ & 30 & 20 & 10 & 5 \\
\hline PMMAD-Bus & 10 & $120 \mathrm{Vdc}$ & 4 & 42 & 6 & 5 \\
\hline PMAD-PLR & 125 & $500 \mathrm{Vdc}$ & 20 & 25 & 6 & 5 \\
\hline PMAD-AUX & 28 & $400 \mathrm{Vac}$ & 42 & 3 & 20 & 30 \\
\hline
\end{tabular}

\section{Alternator Voltage}

The alternator-to-PMAD cable represents the heaviest of the cable assemblies due to its long length and large wire size. The alternator power and operating voltage dictates the conductor current rating. For a given power level, higher alternator voltage results in a lower current rating and mass for the power cabling. However, the higher alternator voltage creates other concerns relative to space-rated electronic parts availability (switchgear, etc.) and corona arcing.

Figure 11 shows alternator-to-PMAD cable mass as a function of alternator voltage assuming $100 \mathrm{kWe}$ distribution and 30 meter transmission distance. The reference case at $600 \mathrm{Vac}$ alternator output is shown at the "knee" of the cable mass curve. A 100 Vac alternator voltage would result in a $260 \mathrm{~kg}$ cable mass penalty. If the alternator voltage was doubled to $1200 \mathrm{Vac}$, the resulting cable savings would only be $24 \mathrm{~kg}$, and additional concerns would be raised with respect to corona and parts availability.

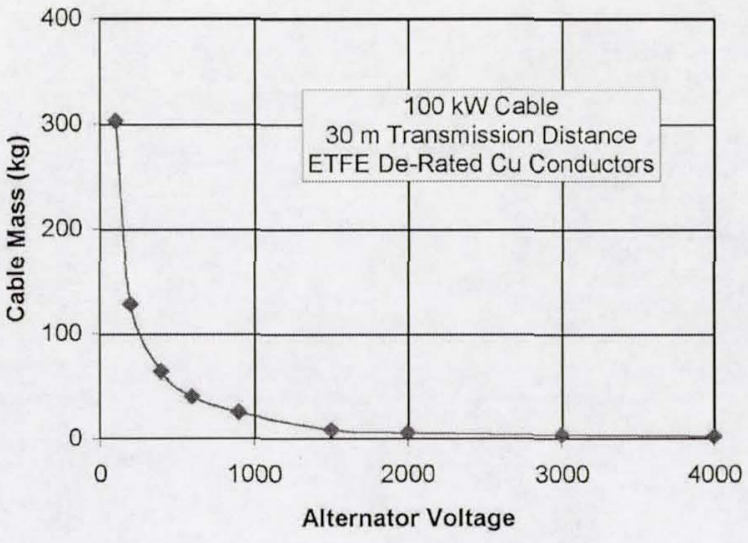

Figure 11. Cable Mass Versus Alternator Voltage

\section{MASS AND EQUIPMENT LIST}

Table 4 presents the power conversion mass and equipment list. The total mass was $2818 \mathrm{~kg}$, or $28 \mathrm{~kg} / \mathrm{kWe}$. The mass fractions for the Brayton units, HRS, and PMAD are approximately 45,30 , and $25 \%$, respectively. The reactor and shield subsystem adds about $1300 \mathrm{~kg}$ for a total power system mass of $4115 \mathrm{~kg}$, or $41 \mathrm{~kg} / \mathrm{kWe}$. The table shows the approximate location of the equipment on the vehicle: forebody (reactor end), truss, or aftbody (payload end). A short description of the equipment is provided in the right-hand column.

\section{CONCLUSION}

The Jupiter Icy Moons Orbiter mission is currently under study by the Office of Space Science under the Project Prometheus Program. JIMO is examining the use of NEP to carry scientific payloads to three Jovian moons. A potential power system concept includes dual $100 \mathrm{kWe}$ Brayton converters, a deployable pumped loop heat rejection subsystem, and a 400 Vac PMAD bus. Many trades were performed in arriving at this

Table 4. Power Conversion Mass List

\begin{tabular}{|c|c|c|c|c|c|}
\hline Power Comversion (kg) & Location & & & 2818 & 100 kWe system \\
\hline Brayton Power Generation & & & & 1280 & $1.2 \times 1.4 \times 2.6 \mathrm{~m}$ total assembly \\
\hline Turboalternators & Forebody & 2 & 136 & 272 & 50 KWe nomínal, 100 KWe max per unit \\
\hline Recuperators & Forebody & 2 & 243 & 486 & HeXe to HeXe, cross-flow, Inconel \\
\hline Gas Coolers & Forebody & 2 & 178 & 355 & HeXe to NaK, counter-flow, stainless steel \\
\hline Gas Ducting & Forebody & - & $15 \%$ & 167 & $15 \%$ of components, Inconel and stainless steel \\
\hline Heat Rejection System & & & & 854 & \\
\hline Main Radiator Wings & Truss & 2 & 234 & 468 & 2-sided, $85 \mathrm{~m} 2$ per wing, C-C panels wiHPs, $2.75 \mathrm{~kg} / \mathrm{m} 2$ \\
\hline Radiator Fluid Pumps & Forebody & 4 & 24 & 96 & 2-string, redundant EM pumps \\
\hline Radiator Plumbing & Truss & 2 & 75 & 150 & NaK-78, stainless steel piping, accumulator \\
\hline Deployment Mech. \& Structure & Truss & - & $30 \%$ & 140 & $30 \%$ of panels, scissor mechanism (i.e. ISS) \\
\hline Power Management \& Distribution & & & & 684 & \\
\hline Controls, Electronics, Switchgear & Aftbody & 2 & 193 & 386 & 2 channels in one $50 \times 50 \times 75 \mathrm{~cm}$ box \\
\hline Parasitic Load Radiator & Aftbody & 2 & 36 & 72 & $6 \mathrm{~m} 2$ total surface area, $500^{\circ} \mathrm{C}$ \\
\hline Alt to PMAD Cabling & Truss & 2 & 44 & 88 & $2 \times 100 \mathrm{kN}, 600 \mathrm{Vac}, 30 \mathrm{~m}$ (incl entl, ground wires) \\
\hline PMAD to PPU Cabling & Aftbody & 2 & 7 & 14 & $2 \times 125 \mathrm{~kW}, 400 \mathrm{Vac}, 10 \mathrm{ch}, 5 \mathrm{~m}$ \\
\hline PMAD to Bus Cabling & Aftbody & 2 & 3 & 6 & $2 \times 10 \mathrm{~kW}, 120 \mathrm{Vdc}, 5 \mathrm{~m}$ \\
\hline PMAD to PLR Cabling & Aftbody & 2 & 14 & 28 & $2 \times 125 \mathrm{kN}, 500 \mathrm{Vdc}, 5 \mathrm{~m}$ \\
\hline PMAD to Aux Cabling & Truss & 2 & 9 & 18 & $2 \times 28 \mathrm{kN}, 400 \mathrm{Vac}, 30 \mathrm{~m}$ (pumps, heaters, motors) \\
\hline PMAD Radiator & Aftbody & 2 & 36 & 72 & $6 \mathrm{~m} 2$ total surface area, $60^{\circ} \mathrm{C}$ \\
\hline
\end{tabular}


candidate power system concept. System-level studies examined design and off-design operating modes, determined startup requirements, evaluated subsystem redundancy options, and quantified the mass and radiator area of reactor power systems from 20 to $200 \mathrm{kWe}$. In the Brayton converter subsystem, studies were performed to investigate converter packaging options, and assess the induced torque effects on spacecraft dynamics due to rotating machinery. In the HRS, design trades were conducted on heat transport approaches, material and fluid options, and deployed radiator geometries. In the PMAD subsystem, the overall electrical architecture was defined and trade studies examined distribution approaches, voltage levels, and cabling options.

\section{ACKNOWLEDGMENTS}

This work was performed for NASA Headquarters, Office of Space Science (Code S) under the Project Prometheus Program. The study was supported by personnel from the Jet Propulsion Laboratory, Glenn Research Center, Marshall Space Flight Center, Los Alamos National Laboratory, Sandia National Laboratory, and Oak Ridge National Laboratory. The PMAD concept was developed principally by the Electrical Systems Development Branch at GRC, and in particular James Soltis, Arthur Birchenough, and Greg Kimnach. The ion propulsion concept was developed under the guidance of Steve Oleson with support from the GRC On-Board Propulsion Branch.

\section{REFERENCES}

1. Mason, L.S., "A Comparison of Brayton and Stirling Space Nuclear Power Systems for Power Levels from 1 Kilowatt to 10 Megawatts," NASA/TM-2001-210593, January 2001.
2. Davis, J.E., "Design and Fabrication of the Brayton Rotating Unit,” NASA CR-1870, March 1972.

3. Dobbler, F.X., et al., "Analysis, Design, Fabrication and Testing of the Mini-Brayton Rotating Unit (Mini-BRU)," NASA CR-159441, April 1974.

4. Staff of the Solar Dynamic Power Systems Branch, "Solar Dynamic Power System Development for Space Station Freedom," NASA RP-1310, July 1993.

5. $\mathrm{Yu}, \mathrm{A} ., \mathrm{Hewston}, \mathrm{A}$., and Le, D.K., "Preliminary Torque Analysis of Closed Brayton Cycle Rotordynamics on a Conceptual Nuclear Electric Propulsion Vehicle," NASA TM, in process.

6. Lockheed Martin Missiles and Fire Control Website, November 2002. http://www.missilesandfirecontrol.com/ our_products/productdevelopment/ SPACESTATION/product-spacestation.html

7. Truscello, V.C. and Rutger, L.L, "The SP-100 Power System," American Institute of Physics Conference Proceedings 246. 9th Symposium on Space Nuclear Power Systems. Albuquerque, NM, 1992.

8. Juhasz, A.J., "Design Considerations for Lightweight Space Radiators Based on Fabrication and Test Experience With a Carbon-Carbon Composite Prototype Heat Pipe," NASA/TP_-98207427/REV1, September 2002.

9. Mason, L.S., Shaltens R.K., and Espinosa, W.D., "Experimental Data for Two Different Alternator Configurations in a Solar Brayton Power System," NASA TM-107509, July 1997. 